\title{
Đồng chí Phạm Minh Chính nhậm chức Bí thư Tỉnh ủy Quảng Ninh
}

QNP - Sáng nay, 15-8, tại Tỉnh ủy Quảng Ninh đã diễn ra Lễ công bố Quyết định của Bộ Chính trị về việc phân công đồng chí Phạm Minh Chính, Uỷ viên $\mathrm{BCH}$ Trung ương Đảng, Thứ trưởng Bộ Công an giữ chức vụ Bí thư Tỉnh uỷ Quảng Ninh nhiệm kỳ 2011 - 2016.

Tham dự Lễ công bố quyết định của Bộ Chính trị có đồng chí Tô Huy Rứa, Ủy viên Bộ Chính trị, Bí thư Trung ương Đảng, Trưởng Ban Tổ chức Trung ương; đồng chí Vũ Đức Đam, Ủy viên $\mathrm{BCH}$ Trung ương Đảng, Bộ trưởng Chủ nhiệm Văn phòng Chính phủ; các đồng chí là lãnh đạo Ban tổ chức Trung ương, lãnh đạo Bộ Công an; lãnh đạo tỉnh Quảng Ninh.

Tại buổi Lễ, đồng chí Trần Lưu Hải, Uỷ viên Trung ương Đảng, Phó Trưởng Ban tổ chức Trung ương, thừa uỷ quyền của Bộ Chính trị, Ban Bí thư, Ban Tổ chức Trung ương đã công bố Quyết định số 220-QĐNS/TW ngày 4-8-2011 về việc phân công đồng chí Phạm Minh Chính, Uỷ viên $\mathrm{BCH}$ Trung ương Đảng, Thứ trưởng Bộ Công an giữ chức vụ Bí thư Tỉnh uỷ Quảng Ninh nhiệm kỳ 2011 - 2016, thay đồng chí Vũ Đức Đam, được điều động giữ chức vụ Bộ trưởng, Chủ nhiệm Văn phòng Chính phủ.

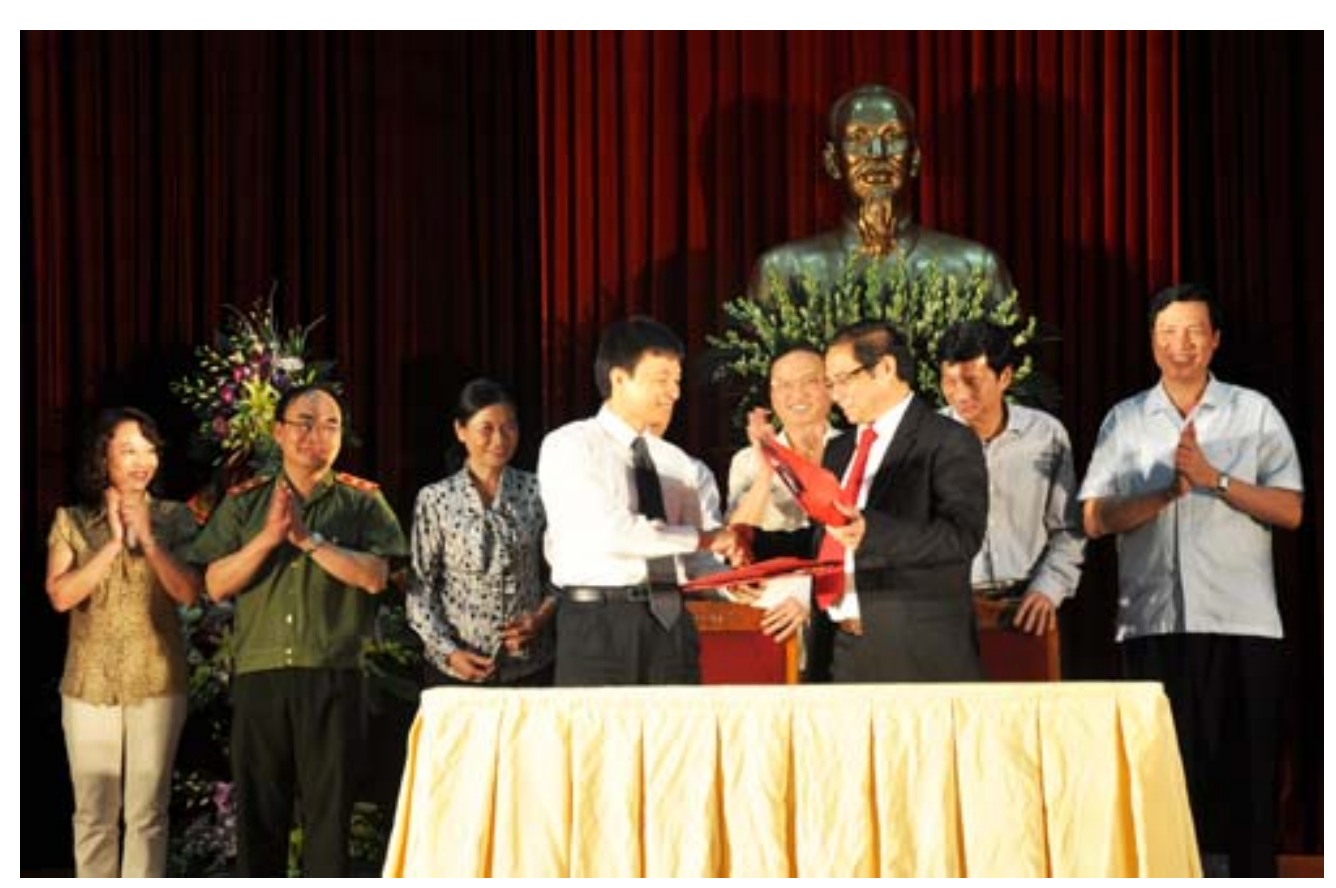

Đồng chí Vũ Đức Đam, nguyên Bí thu Tỉnh ủy và đồng chí Phạm Minh Chính, tân Bí thư Tỉnh ủy ký kết biên bản bàn giao công tác.

Phát biểu tại buổi lễ, đồng chí Tô Huy Rứa, Ủy viên Bộ Chính trị, Bí thư Trung ương Đảng, Trưởng Ban Tổ chức Trung ương đánh giá: qua quá trình hoạt động và các môi trường làm việc, đặc biệt ở cương vị Thứ trưởng Bộ Công an, đồng chí Phạm Minh Chính đã phát huy tinh thần năng động sáng tạo, thể hiện được năng lực và phẩm chất của người lãnh đạo.

Qua phân tích và lựa chọn, Bộ Chính trị đã quyết định phân công đồng chí Phạm Minh Chính, 
Ủy viên $\mathrm{BCH}$ Trung ương Đảng, Thứ trưởng Bộ Công an giữ chức Bí thư Tỉnh ủy tỉnh Quảng Ninh. Đồng chí Tô Huy Rứa khẳng định: Quảng Ninh là môi trường, điều kiện tốt để đồng chí Phạm Minh Chính rèn luyện và phát triển, đồng thời tin tưởng rằng, với sự hỗ trợ, giúp đỡ của Đảng bộ, nhân dân Quảng Ninh, đồng chí Phạm Minh Chính sẽ hoàn thành nhiệm vụ, trọng trách được giao.

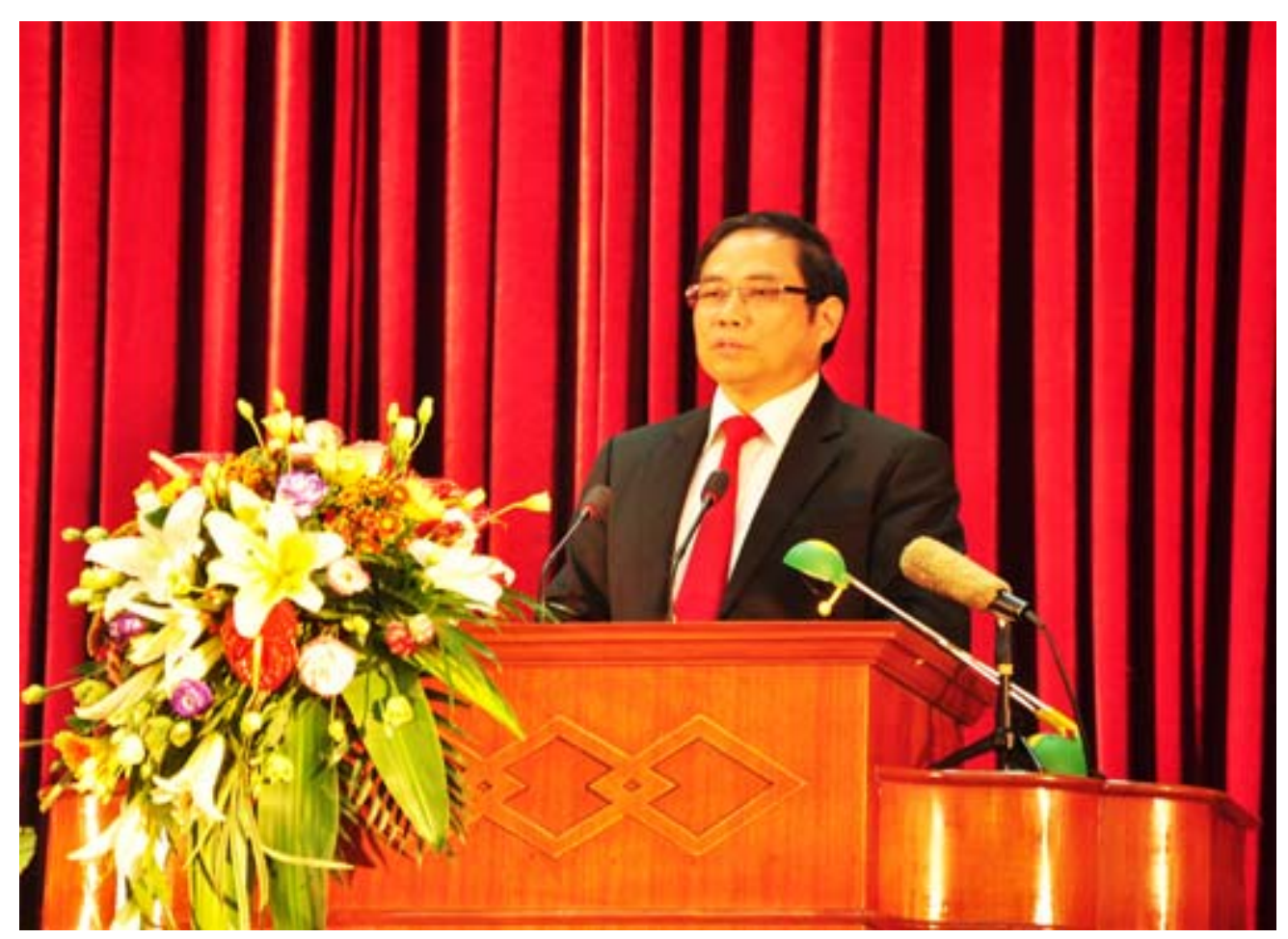

Đồng chí Phạm Minh Chính, Ủy viên BCH Trung ương Đảng, Bí thu Tỉnh ủy Quảng Ninh phát biểu nhậm chức.

Với tất cả sự trân trọng và tình cảm chân thành, đồng chí Phạm Minh Chính, Ủy viên $\mathrm{BCH}$ Trung ương Đảng, Bí thư Tỉnh ủy Quảng Ninh, cảm ơn sự tin tưởng của Đảng, Nhà nước và tỉnh Quảng Ninh, đồng thời xác định đây là trọng trách lớn lao và hứa sẽ nỗ lực tối đa để hoàn thành các nhiệm vụ được giao.

Với tinh thần sẵn sàng đón nhận nhiệm vụ do Đảng phân công, đồng chí Phạm Minh Chính mong muốn nhận được sự hỗ trợ tích cực của các đồng chí trong Ban Chấp hành, Ban Thường vụ Tỉnh ủy, các đồng chí là lão thành cách mạng, nguyên là cán bộ chủ chốt của tỉnh, các đồng nghiệp, cán bộ, Đảng viên và nhân dân trong tỉnh, để xây dựng Quảng Ninh ngày càng phồn vinh và phát triển, đóng góp vào sự phát triển chung của cả nước.

Hôm qua, 14-8-2011, đồng chí Phạm Minh Chính đã đến đặt vòng hoa tại Đài tưởng niệm các anh hùng liệt sỹ tại thành phố Hạ Long; dâng hương tưởng nhớ các anh hùng liệt sỹ tại Nghĩa trang liệt sỹ Hà Tu và thăm hỏi một số cán bộ lão thành cách mạng, cán bộ nguyên là lãnh đạo tỉnh Quảng Ninh qua các thời kỳ./. 
Đồng chí Phạm Minh Chính, sinh ngày 10/12/1958 tại xóm Hoa Trường, xã Hoa Lộc, huyện Hậu Lộc, tỉnh Thanh Hóa. Là kỹ sư xây dựng, Phó Giáo sư, Tiến sỹ Luật, Trung tướng. Hiện nay đồng chí là Ửy viên Ban Chấp hành Trung ương Đảng Cộng sản Việt Nam, Bí thư Tỉnh ủy Quảng Ninh; nguyên Thứ trưởng kiêm Tổng Cục trưởng Tổng Cục Hậu cần - Kỹ thuật, Bộ Công an.

QNP 15/8/2011 


\section{Tài liệu tham khảo:}

[1] Phạm Minh Chính. (2010). Quan hệ công chúng (PR) trong hoạt động kinh tế, khoa học công nghệ và môi trường. Nxb Chính trị Quốc gia, Hà Nội.

[2] Phạm Minh Chính, Vương Quân Hoàng. (2009). Kinh tế Việt Nam: Thăng trầm và đột phá. Nxb Chính trị Quốc gia, Hà Nội.

[3] Phạm Minh Chính, Vương Quân Hoàng. (2008). Bối cảnh tài chính Việt Nam $1997-$ 1998 và 2007-2008: Khoảng cách và biến đối. Nghiên cứu Kinh tế, 48(7), 3-24. 